\title{
New ruralities - old gender dynamics? A reflection on high-value crop agriculture in the light of the feminisation debates
}

\author{
S. Bieri \\ Centre for Development and Environment, University of Bern, Bern, Switzerland \\ Correspondence to: S. Bieri (sabin.bieri@cde.unibe.ch)
}

\begin{abstract}
Received: 6 January 2014 - Revised: 5 November 2014 - Accepted: 11 November 2014 - Published: 11 December 2014
\end{abstract}
\begin{abstract}
While a remarkable continuity in smallholder agricultural production has been identified, the shift from subsistence orientation towards more wage dependence appears in a different light when analysed under a gender perspective. "Feminisation" has been a catchphrase to characterise some of these processes; however, the debate has been subject to overgeneralisation, and can only inadequately grasp the gender dynamics in what has been referred to as "new ruralities". Illustrated for high-value crop production as an expression of agricultural transition in the Global South, this contribution offers a critical account of the feminisation thesis. Instead of discarding the notion of feminisation, it advocates a reassessment of its potential as a comprehensive framework against which empirical findings can be reflected. While conventional uses of the feminisation thesis have, in their great majority, come up with the conclusion that for women it can always only get worse, I propose a perspective which reveals gains and risks and how they are shared between men and women as they engage in new agricultural labour markets. This perspective rests on a methodology for case-based, comparative studies developed in this paper as a contribution for assessing the nature of agricultural transition and to investigate the qualitative change associated with new ruralities. A distinctive appreciation of the substance of agricultural change for different members of the rural society - namely men and women, but also different men, and different women - is the premise for overcoming barriers to shared development, and for framing effective governance in the context of global development.
\end{abstract}

\section{Introduction}

Rural spaces in the Global South are transforming dramatically. The drivers, effects and quality of this transformation are the subject of a number of recent publications, including this special edition of GH, fuelling an increasingly intense debate on agriculture and sustainable rural livelihoods which has gained traction since the 2007 financial and subsequent economic crises (Babigumira et al., 2014; Collier and Dercon, 2014; Diao et al., 2010; Hazell et al., 2010; Henley, 2012; Jayne et al., 2010; Kerr, 2012; Riggs and Vandergeest, 2012). Questions on gendered effects and genderspecific realities in the rural contexts form a prominent part of these debates, driven by the assumption that women's roles in agriculture are substantial but inadequately documented and poorly understood. The range of positions towards these questions opens basically between two extremes: first the premise that women might be most negatively affected by agricultural liberalisation and commoditisation, leaving them ever more vulnerable, and second that, by pulling the right triggers, women could, by their virtues, eventually be the ones to free rural areas from the poverty trap (Baden, 2013; Meinzen-Dick, 2010; Pretty et al., 2010; Prügl et al., 2013; Rahman, 2010; Zaccaro, 2011).

"Feminisation of agriculture" has been the catchphrase to illustrate some of the dynamics referred to above. Originating in the poverty debate, the term "feminisation" has proliferated in much of the literature on agriculture and development (De Schutter, 2013; WDR, 2012). While the term seems attractive, it is often used with insufficient empirical substance and does not provide an analytical framework to actually explain and understand the gendered processes that 
are at the heart of the dynamics referred to above. This is reinforced by a general under-information on rural poverty and its gendered structure at the intersection of agriculture and employment - a field which, according to Carlos Oya, is saturated with conventional wisdom rather than evidence (Oya, 2013). At the same time the need for more robust and detailed information on rural poverty and inequality has been articulated, along with calls to take stock of the heterogeneity of the economies of rural spaces (IFAD, 2011). Furthermore, initiatives for differentiated pathways to sustainable development have surfaced (Leach et al., 2010).

While not offering empirical data to answer these calls, the present contribution attempts to illustrate the notion of new ruralities as referred to by Rauch and others in this volume in the light of recent trends in rural employment in the Global South and its alleged feminisation. By adopting the gender perspective, the article will add to the discursive tension between the supposed "remarkable continuity" of smallholder agricultural systems and the dramatic transformations these systems have undergone (cf. article by Rauch). Continuity and change are the ends between which gender relations have materialised over time, forming the analytical axes against which their dynamics and consistency can be compared. A gender-differentiated analysis of social and economic shifts tells another, different story about development - a story which has often, and too quickly, been labelled as feminisation.

I will argue along with others that the widespread classification of shifting gender relations in agriculture as feminisation does not adequately capture the complex dynamics within and outside households in the context of sustaining rural livelihoods (Chant, 2007a, b, 2010). However, the bulk of studies promising to provide "gender analyses" have not been more illuminating, either. The reason for this lies with the fact that the use of "gender" has become utterly prominent, if not mandatory. This trend has eroded the analytical potential of the gender perspective. Against this background, the aim of this paper is to challenge the current inflation of the feminisation hypothesis and to offer a methodological framework for studies of agricultural change under a gender perspective.

By providing ideas on how to frame the gendered nature of agricultural transition, this article shall contribute to the overall aim of this issue in terms of forging conceptual tools for the analysis of rural transformation and to assess the nature of the purported new ruralities, particularly in view of the called-for "multidimensionality" of the analyses. This includes a methodological outline to gauge outcomes of shifting agricultural production in high-value crops and related labour market transformations. The proposed methodology is envisaged to illuminate the re- and decomposition of gendered relations as rural households move towards more wage dependence, and will thus yield a more nuanced picture instead of a premature classification of these processes as feminisation. The overall aim of the paper is to present ideas for a framework for investigating high-value crop production, rural employment and its effects on intra-household relations. By informing research on rural labour markets, such a framework could contribute to identifying gendered mechanisms of moving in and out of poverty, including the terms on which different social groups exit agriculture. Results could help to define measures for effective and sustainable poverty alleviation, including asset building and the enhancement of rural women's and men's choices.

The article will offer an extended discussion of the feminisation debate in recent feminist development literature, followed by a section on women's increasing employment in commercialised agriculture. Initial thoughts on how comparative data beyond the case-study level can be gained in order to illuminate the gendered production of new ruralities at the intersection of agriculture and wage employment for the case of high-value crops will conclude the article.

\section{The feminisation debate}

The term of feminisation has gained traction in recent debates on globalisation and development. Coined by Diane Pearce in the late 1970s (Pearce, 1978), it was brought firmly into the political discourse at the Fourth International Women's Conference in Beijing in 1995. Its prevalence in debates on poverty and development has largely been unquestioned, and, along with the unsubstantiated figure of $70 \%$ as the total poverty incidence in women, also disseminated in Beijing, has dominated the debate for years.

Within its extensive use, the notion of feminisation has been associated with three distinct meanings: first, that women compared to men have a higher incidence of a given item; second, that the incidence of this item is increasing for women; and third, that women's experience is more marked than men's (Chant, 2007b; Johannsson Wennerholm, 2002). There are several problems that arise from this definition. With respect to the incidence the question of the benchmark is often unclear. Is the incidence compared to men or to a previous state; are we talking about absolute or relative numbers? In the case of poverty, gender-disaggregated data were not available for the majority of regions. Poverty data at the household level however do not answer the question of female poverty. To circumvent the data constraints, the focus was shifted on female-headed households who then became the icon for "the poorest of the poor" (Chant, 2007a). This is problematic because female-headed households, depending on the reason of being single-headed, are in very different positions relative to male-headed households, and because of great regional differences. More so, the prominent association of female-headed households with poverty also conveys a conformist ideology about family norms.

With respect to the second point, data are often critical, so comparisons are hardly reliable. In other words, is women's engagement in agriculture actually increasing, or is it due 
to recent awareness of their activities that they appear to be more numerous?

For the last criterion, empirically grounded data are even harder to get, let alone beyond anecdotal level, and for the case of Latin America Chant did not find evidence to sustain the idea (Chant, 2010).

A further shortcoming of most use interpretations of feminisation is its limitation to numeric dimensions. The feminisation thesis entails more than numbers. It also refers to changes in structures and processes - changes towards standards and norms which, in the past, and conventionally, have been associated with a female realm or women more generally. For example, in the context of employment, flexibilisation, downgrading of jobs or reduction of benefits has have increasingly affected a wide range of jobs, not only those in typically female sectors. This trend has been referred to as feminisation too, and it obviously concerns men as well. Although both men and women are negatively affected by downward pressure on employment conditions, female workers usually struggle with additional burdens due to their involvement in unpaid labour and care work, an aspect that is captured by the notion of the feminisation of responsibility and obligations (Chant, 2010).

For agriculture, similar developments can be identified, but each of these would need careful empirical examination before handing out the feminisation-label (Deere, 2005). As Sylvia Chant argues, feminisation is not a useful frame for effectively addressing the complexity of gendered experience; on the contrary, it contributes to stereotyping and unwarranted simplifications. Chant has probably been the most prominent voice in a critical assessment of the so-called feminisation of poverty, and her research has been at the root of a significant shift of how poverty and gender are being deliberated in the context of development geography, and development studies more generally (Chant, 2006, 2007b). This has been particularly evident with the debate on female-headed households which have come to represent the most deprived social entities, the poorest of the poor (Chant, 2007a). While framing poverty in the light of single mothers has been very successful in terms of mobilisation and campaigning for aid money, Chant cautions against an uncritical uptake of this perspective, not least because it rests on a rather weak empirical basis, is under-theorised and suffers from overgeneralisation. In her own research from the Philippines, The Gambia and Costa Rica she derives a much more detailed account of the status of single mothers and female-headed households.

Despite its inadequacies in terms of contextualisation, theoretical precision and empirical reliability, the concept has proliferated into a range of thematic and sectoral development debates, among which agriculture ranks rather prominently.

In the next section I will discuss how the shift to commercialised agriculture, a trend in a number of developing countries, creates new employment opportunities, particularly for women. It will be discussed how women have engaged in these labour markets, how this has impacted their positions relative to men and whether feminisation adequately captures the respective dynamics.

\section{Feminisation of agricultural production}

In the course of the powerful global drivers of change and their dramatic impacts on rural spaces, small-scale, subsistence-oriented agriculture remains a vital source of resilience and livelihoods, particularly in the Global South. It is widely recognised that agricultural activities are a primary engine of rural development and growth, providing a critical route out of poverty (Doss, 2011; IFAD, 2011; WDR, 2013). Agriculture is also by far the most important source of employment for men and women in the poorer regions of the globe. Eighty-six percent of the world's rural population depend on farming; 450 million are agricultural wage workers (FAO, 2010a, b; IAASTD, 2009; OECD, 2009). However, with large shares of female subsistence farming, agriculture in the Global South is also viewed as underperforming (FAO, 2011), and high-profile development policy platforms have issued demands for more capital-intensive commercial agriculture, promoting alternative forms of employment that can generate higher returns for workers (WDR, 2012, 2013). Additionally, the share in traditional export crops such as tea, coffee, cotton, and grains has decreased over the past 2 decades; shocks and severe dumps in prices have demonstrated the vulnerability resulting from concentration on only few crops (UNRISD, 2005).

To counteract this, national governments have increasingly embarked on production of high-value crops for export, which have seen a rapid expansion in a number of developing countries. This has to be seen within the larger goals of economic policy, which have increasingly prescribed the reduction of inflation, a cut-back of household budgets and export orientation of national economies. A number of developing countries, such as Kenya or Ecuador, have reshaped their agricultural policy by establishing labour-intensive production of high-value crops such as flowers, vegetables and spices, which have become a major contribution to the sector (Barrientos, 2003). The movement of labour into higherincome activities was an important feature of transformation in emerging economies (Bramall, 2008). While the ratio of traditional crops in these countries (grains, tea, coffee, cotton) has steadily declined (Dolan and Sorby, 2003), nontraditional agricultural exports (NTAEs) have been expanding at a rapidly growing pace over the last 2 decades, playing a key role in creating wage labour and, notably, stimulating high levels of female employment in rural areas (Barham et al., 1992; Barrientos, 2007; Ferm, 2008; Sang, 2010).

Although the effect varies greatly by country and product, the agricultural transition implied therein relies heavily on female agricultural workers (UNRISD, 2005; Barrientos, 2003). Many high-value agrifood chains are charac- 
terised by increasing levels of female participation (Dolan and Sorby, 2003). NTAEs have offered an entry into paid work for a large portion of rural women, and an alternative for young women apart from substitute sources of employment or early marriage. NTAEs include a number of products - horticulture; floriculture; processed food products; and spices such as vanilla, cardamom, ginger and chilli - many of which have gained importance in terms of their contribution to growth and employment in developing countries over the last 2 decades. High shares of female employees in horticulture have been reported in a number of countries, such as Zimbabwe (91\%), Tanzania (57\%), Ecuador (70 \%), Kenya (75\%) and Uganda (85\%) (Dolan and Scott, 2009; Wilkinson-Weber, 2004). However, in some cases, results in terms of job creation have been disappointing: "Their land is needed, but their labour is not" ( $\mathrm{Li}, 2011: 286)$. The decision not to employ the people whose land has been taken, and to recruit labourers from outside the region instead, is justified by framing the local population as lazy (Aatas, 1977, in: $\mathrm{Li}$, 2011:286).

While opportunities for women have increased, employment conditions appear to be critical and highly unequal ( $\mathrm{Li}$, 2011; Razavi et al., 2012). The emergence of high-value agriculture in developing countries goes hand in hand with the restructuring of work regimes; feminisation and flexibilisation are at the heart of this process (FAO, 2011). The pressure global producers face to reduce costs while keeping up quality standards is transferred to local workers in the form of low wages, casualised labour, lack of labour rights and restricted union representation. Moreover, women face gendered constraints such as their socially ascribed skills, which are less rewarded than men's, as well as obstacles to moving into more advantageous positions (Chhachhi, 1999; FAO et al., 2010b). The question is therefore whether what appears to be a more extensive presence of women in the transforming agriculture sector contributes to increased and long-term well-being of these women and their families.

Critical voices point to the risks of exacerbating rather than reducing poverty and vulnerability in the course of agricultural commercialisation, for example through loss of control over land and labour; frequent crises and increased volatility of prices; and intensified use of natural resources - particularly water - on which the rural poor depend (Li, 2011; Wichterich, 2010). Critical accounts highlight the distress-driven character of women's engagement. Women often take up income-generating activities when urgent household needs emerge, such as debt repayment or medical expenses (Whitehead, 2009). This indicates that women face a gender disadvantage with regard to building assets from their employment. Razavi suggests evaluating the choices of women and men against a series of constraints arising from the urgency of domestic needs, the low income potential of smallholder production and the prevailing perception of women's labour as unskilled, regardless of the tasks involved in an activity (Chhachhi and Herrera, 2007; Faulkner and Lawson, 1991;
Razavi, 1999, 2009). Not least, the critics also highlight the instrumentalist character of the concept of women's economic empowerment as it is used by development agencies (Jones, 2012; Kabeer, 2012).

$\mathrm{Li}$ (2011) raises questions as to whether extracting cheap labour might be difficult in contexts where people still have access to land and thus options they might prefer over wage employment. This points to the need of linking the current surge in research on shifting tenure regimes and large-scale land acquisition with the debate on export-led agriculture and new ruralities - a suggestion recently made by Hall et al. (2011).

It thus appears as if the road out of poverty has turned into a dead end, where women get stuck in low-value jobs, which, instead of increasing their independence and their autonomy, force them to take on even more responsibility in the less stable environment of wage dependence.

However, other scholars underline that women's engagement in paid work has improved their standing within their communities and has widened their choices and opportunities (De Haan and Lakwo, 2006; Kabeer, 2012; Alam, 2012). Positive welfare effects of the labour-intensive (as opposed to land-intensive) horticultural export chains in sub-Saharan Africa have been documented especially for poor households, who can more easily build assets based on labour than product markets. Moreover, value chains established by large firms - so-called global production networks - seem to offer better working conditions and bring in measures to promote gender equality (Kabeer et al., 2011; Maertens et al., 2012). Indeed, the creation of new forms of employment and sources of income for the rural population, particularly women, appears to be a positive outcome of this development, giving them choices other than migration for domestic work and possibly improving single women's position in terms of having a say in marriage arrangements (Smith et al., 2004; Lavers, 2012).

Research on the shifting patterns of rural employment and their gendered implications is limited by a lack of data, particularly on rural women's employment. This lack is partly due to the fact that these issues lie at the intersection of agriculture and labour concerns and are not adequately addressed across the two sectors. Indeed, a number of ill-founded and oversimplified assumptions about the rural labour market have shaped the discourse on rural employment and rural workers (Oya, 2010). Information is frequently unreliable, such as in the case of Latin America, where data suggest an increase in rural women's economic activities between 1980 and 2000. However this is simply a reflection of their previous under-enumeration (UNRISD, 2005). Furthermore, while information on incomes might be available, substantial knowledge on well-being is lacking. In-depth and comparative research is thus needed (Whitehead, 2009). How such research could be designed and preliminary ideas on methodological challenges will be the subject of the next section. 


\section{Assessing gender relations and rural employment in high-value crops}

For a recently launched research project ${ }^{1}$ on the gendered developmental outcomes of employment opportunities in the agricultural export sector, we have proposed a case-based, comparative and longitudinal research design. The overall objective of this study is threefold: (1) to analyse how women's and men's livelihood perspectives change with increasing wage dependence in rural areas; (2) to analyse how gender relations are re- and decomposed as people negotiate the effects of change in their private and public engagements; and (3) to offer ideas for the regulation of agricultural transition processes so as to include a majority of the rural population, but in particular those groups with potentially less voice. We used the feminisation concept in its various dimensions in terms of hypotheses against which to reflect our findings.

Within-case as well as cross-case analyses will inform the study with a view to understanding and explaining the gendered effects of agricultural commercialisation and possibly drawing more general conclusions (Hantrais and Mangen, 1998:2). The longitudinal organisation of data collection and analysis in two waves is a key feature of our research design allowing to assess trends, changes and continuities.

In order to meet the standards of a transdisciplinary project, we plan to use innovative methods to bridge qualitative and quantitative techniques and to offer entry points for the integration of non-academic knowledge. Multicriteria mapping entails deliberative appraisal processes to enhance social learning, and fosters political spaces that include the interests of those groups in society who tend to be under-represented in public consultations (Burgess et al., 2007; Stirling et al., 2007).

The tricky questions within this design come with implementation. Four aspects are particularly delicate: (1) categories of informants, (2) sampling strategies, (3) questions and items for surveys and interviews and (4) documentation.

1. The most sophisticated methodological framework will not serve to generate new and more accurate knowledge on the sharing of gains and risks of agricultural commercialisation if the categories of analysis are not critically assessed. Who should actually be included in surveys, and who should be interviewed? Household heads or more members of the household? Women and men together or separate, or women only? Also, it is unclear whether to focus on workers or peasants and, whatever the decision, how they are identified. Responding to the

\footnotetext{
${ }^{1}$ Feminisation, agricultural transition and rural employment: social and political conditions of asset-building in the context of export-led agriculture (FATE). Partnership research with Nepal, Bolivia, Rwanda and Lao PDR. Expected duration: 2014-2020; funded by the Swiss National Science Foundation SNSF and the Swiss Agency for Development and Cooperation. For more information please refer to www.r4d.ch.
}

intersectional character of the project, different generations and ethnicities will be considered. These decisions are crucial and will critically predetermine the research results.

To adequately represent different household positions, at least two people representing the household should be interviewed, and they should be offered a space to guarantee individual and anonymous completion of questionnaires. The potential of electronic devices will be explored to protect the privacy of participants; clearly, this must be carefully weighed against inclusiveness. We insist on collecting original data because labour force surveys seem to rely too much on categories, such as "main job-holding", which inadequately reflect economic realities in rural spaces that are marked by irregularity, multiple occupations and seasonality. Furthermore, traditional accounts of work are based on an industrial model of separated spheres of productive and reproductive work - a separation which often excludes economic activities largely done by women which are categorised as "non-productive". Oya points to the challenge of distinguishing between self-employment and wage employment in rural settings for the case of Africa (2013). On the same line, the (self-)identification of someone as a "worker" might be unclear, resulting in unrealistically low proportions of workers, particularly for sub-Saharan Africa. Most studies seem to focus on smallholders, rather than workers, thereby omitting the fact that in rural areas many people still cultivate, even if only tiny bits of land, although farming is far from providing their livelihoods. Oya's detailed account of why wage employment is underestimated and misunderstood in sub-Saharan Africa is an eye-opening contribution to these problems (Oya, 2013).

2. A purposive sampling strategy for meaningful comparison will be built, whereby a set of countries is selected that not only comprises representative features but also includes variations deemed useful with respect to the dimensions derived from theoretical interest (Seawright and Gerring, 2008:296). The chosen sampling strategy is mainly guided by a "diverse case selection strategy" aimed at maximum variance along relevant dimensions, while also including elements of a "typical case selection" to guarantee the representativeness of the selected cases (Gerring, 2009). This is reflected in the selection of our case-study countries. Four countries on three continents with different but highly dynamic trajectories of export-based agriculture were selected from the UN priority category of least developed, landlocked countries ${ }^{2}$ to constitute the cases: Rwanda, Nepal, Laos and Bo-

\footnotetext{
${ }^{2}$ The mandate to the high representative of least developed landlocked countries (UN-OHRLLS) was issued in 2001, http://www. unohrlls.org/ (last accessed 1 July 2012).
} 
livia. They are land-locked and mountainous countries where agriculture typically constitutes the backbone of the economy. In all cases, the governments have embarked on development strategies and poverty reduction plans, featuring an increase in agricultural production and efforts to shift to export-led production and nontraditional crops as important elements. However, the emphasis given to these initiatives and the shape they have taken differs considerably between cases. For example, they are situated at different points along the continuum of accountability towards citizens at one extreme and towards capital (foreign and domestic) at the other (Prügl et al., 2013). Bolivia's national development plan foresees comprehensive protection schemes to cushion the process of livelihood diversification and agricultural transition. The government of Nepal builds on cooperatives as pillars to support the implementation of its trade liberalisation strategy and promotion of inclusive growth. By contrast, Rwanda and Lao People's Democratic Republic (PDR) have seen less consideration of social policy, and, while liberalisation has had tremendous effects on these countries' economies, political participation has remained limited. More similarities are constituted by the classification of the countries as least developed according to the 2012 Organisation for Economic Co-operation and Development (OECD) Development Assistance Committee (DAC) list. Particularly for women from poor regions and with low skills, agriculture remains the main source of employment and is seen as a major road out of poverty and towards inclusive development. While all four countries are signatories to the Committee on the Elimination of Discrimination against Women (CEDAW) and have elaborated gender equality strategies, their (in)effectiveness is expressed in their relatively low ranking on the Gender Inequality Index (Rwanda: 76; Bolivia: 97; Lao PDR: 100; Nepal: 102 out of 186). As land-locked countries, they have embarked on highvalue crops for export more recently than some of their neighbouring countries, allowing for the examination of initial effects of this type of agricultural transition as well as ex post judgements of pre-NTAE situations. They all benefit from the shift of consumer markets to the emerging economies of the Global South, particularly their economically powerful neighbours like China or Brazil. In all four cases, an increase in agricultural exports in both absolute and relative terms can be identified as well as an increase in area used for high-value crops and the emergence of new product ranges, some of which have seen a remarkable increase in production (e.g. cut flowers in Rwanda, ginger in Nepal or cassava in Lao PDR), while others are considered to have great potential (e.g. passion fruit in Rwanda).
Variance is offered through the degree of market integration. The countries have pursued economic liberalisation to different extents and adhering to different models. Liberalisation processes have included trade liberalisation; improved standards of local produce; membership in regional economic communities; deregulation of the labour market; creation of incentives, such as exemption from labour or environmental protection standards to attract foreign investments; and preparations for increased export orientation (rankings on the World Bank's doing-business list: Rwanda: 55; Nepal: 108; Bolivia: 155; Lao PDR: 163, out of 185). The shares of foreign direct investment in GDP range from $0.5 \%$ (Nepal) and $0.6 \%$ (Rwanda) to $2.5 \%$ (Bolivia) and even $12.9 \%$ (Lao PDR). The seemingly contradictory numbers for the case of Lao PDR point to the influence of China in Lao's economic development.

Population density and the role of the state in land management determine whether their development strategies focus more on land- and resources or on labourintensive growth. While two of our case-study countries are very densely populated (Rwanda, Nepal), making land a scarce resource, the other two have less pressure on land. One of the main aspects in which the four countries differ is their political and institutional settings regarding the labour market, ranging from intensive to extensive labour market policies. Finally, in terms of diversity the countries follow very different pathways when it comes to the inclusion of ethnic minorities. With regards to institutions and gender equality, the Social Institutions and Gender Index (SIGI) accounting for institutional aspects of gender equality spreads the four between 13 (Bolivia) and 65/66 (Rwanda/Lao PDR respectively, with Nepal in between (38)).

3. As a methodological framework we propose a mixedmethods approach comprising two waves of qualitative as well as quantitative techniques (Cresswell and Plano Clark, 2011). Ellis (2000), among others, advocates mixed methods as a means of illuminating rural labour transformation in a far more comprehensive way than a single investigative standpoint would allow.

Cross-national comparative studies use centrally generated data as their main sources (Harris, 2007). In our case, this procedure seems insufficient, as the database for high-value crops is unreliable due to a variety of reasons (e.g. unregistered forms of work or missing gender-segregated data). To achieve our aims, we will combine quantitative data collection through a panel for systematic and quantifiable measurement of our key indicators (Harris, 2007; Mills et al., 2006) with qualitative in-depth case studies and sociological content analysis to grasp the multi-layered properties and conditions of the problem (Ruiz Ruiz, 2009; Scholz and Tietje, 2002). Quantitative data collection based on two waves 
of large-scale panel surveys will provide original data to assess the contexts, the extent and the meaning of high-value crop employment in each country. An extensive qualitative data collection will precede the panel surveys to generate new understandings of the complex issues at hand and to lay the groundwork for the quantitative assessment.

We will use different interview techniques for the qualitative assessment; in a further qualitative step, life histories and diaries are the tools to drill deep and collect substantial data for within-case comparison (Atkinson, 1998; Yin, 2012). Among the questions to be asked will be self-assessments whereby people judge their own wage and compare it against what they think would be a fair wage (Wallander, 2009).

4. In developing countries, and particularly in rural contexts, a major challenge of these methods is documentation. Using information technology which has quickly been embraced even in poor rural contexts, the research team aims to use film and mobile-phone-supported interview techniques in a participatory way.

To sum up, the comparative approach envisaged should give us information on how the outcomes of agricultural commercialisation in high-value crops are negotiated between different groups in the areas of concern, and in what ways institutional structures frame individual bargaining positions - particularly for those who tend to have less of a voice. This could serve as a model for other assessments of rural transformation aiming at a more nuanced reflection on the de- and recomposition of gender roles in transforming agricultural environments, instead of premature qualification as feminisation. The notion of new ruralities as proposed in this thematic issue could be informed by these types of analyses, highlighting the distinct gender dynamics associated with change and continuity in agricultural livelihoods.

\section{Conclusions}

This paper contributes to the debate on new ruralities by discussing the case of high-value crop production and its alleged feminisation. Whereas gender as an almost compulsory but rather unspecific element of studies in development research has lost much of its edge, the notion of feminisation possibly offers a more concrete hypothesis against which empirical data could be tested. However, this potential can only be explored if the concept is adopted in its various dimensions, which exceeds the perspective on a mere numeric shift between men and women in a particular process. Furthermore, the feminisation thesis, in the majority of its uses, has been associated with the assumption that for women, it can only always get worse. Overused and under-theorised, while resting on a paltry empirical basis, this contribution argues that the widespread notion of feminisation inadequately reflects the dynamic re- and decomposition of relations of gender and generation shaped by economic transformation processes. This paper has proposed ideas for a methodological framework to embrace the feminisation concept more comprehensively in view of appreciating patterns of re- and decomposition of gender relations and the negotiation of respective power positions in the course of massive transformations of rural livelihoods.

By reviewing the literature on feminisation in agriculture, the question was raised of whether feminisation constitutes an adequate framing for the complex shifts in and out of smallholder production systems for rural men and women. The feminisation debate has successfully established the question of changes in the division of labour between men and women in agricultural livelihoods, as they move towards more wage dependence. The term feminisation seems to be quickly at hand as a qualification of effects of agrarian transformation although the empirical substance to underpin the supposed trend is rather shallow. The feminisation lens has been too narrowly focused on an increase of female activities, or, worse, of their visibility in data sets. Most uses of the feminisation thesis refer to a numeric shift between the representation of men and women rather than to a qualitative transformation of employment or livelihoods, such as the downgrading of jobs, flexibilisation, decrease of job benefits and job security, change of responsibilities and work loads. Even less attention has been paid to the insufficient recognition of working contributions seen as "female". Another, rather neglected interpretive element entailed in the feminisation thesis is the shift of responsibilities outside the classic production sphere - for example for food security, housing or schooling. The term has therefore not only been used deficiently; its epistemological potential has also not been explored.

Against this background, a methodological framework to assess the re- and decomposition of gender relations in the context of high-value crops was outlined. It serves as a proposal for generating original data in order to analyse the impacts of high-value crop production on a comparative scale for different segments of the population, namely the (re)negotiation of gender and generation in specific contexts. Thereby the selection of cases combining similarities as well as differences proved to be especially challenging. In order to break the repetitious complaint of missing gender-segregated data and to actually contribute to a more detailed and accurate understanding of rural labour markets, conventional categories for data collection in the fields of agriculture and employment and the proxies selected for surveys need to be revised. This includes careful assessment of definitions such as "worker", "principal activity", "employment", etc., but also the notion of "household", "household head" and "main responsibility". Household representation for surveys should not be limited to just one person, and privacy while answering interview questions should be maximised. 
The value added of a gender-differentiated approach as outlined above is a more detailed appreciation of the nature of agricultural change and the barriers to shared gains and risks, in an overall assessment of the remarkable continuity of smallholder production in the Global South as proposed by Rauch in this volume. The question as to whether new ruralities come with new gender dynamics or, rather, reiterate more traditional gender relations, and what either of these possibilities may hold in store for men and women from different generations, calls for comprehensive studies and the building of qualified evidence. Research aiming at combined largescale and in-depth analyses, a revision of categories - including the researcher's own expectations - in order to come up with comparative, longitudinal data can provide a basis to deliberate transformation strategies that eventually challenge instrumental gender advocacy. Scrutiny of processes which have been denoted as feminisation will reopen and contextualise perspectives on new ruralities and avoid premature judgements on who gains and who loses. The proposed methodology allows for reassessing the question of whether opportunities emerging from export orientation in agriculture offer pathways to women's empowerment, to greater gender equality and improved well-being, or whether these changes result in more obligations to be carried on female and on older shoulders.

After 40 years of gender initiatives in the development community this seems a rather trivial position. Nevertheless, it remains the premise for pinpointing the roots of persistent inequalities, not only between men and women but also within each gender group, and to develop alternative visions for improved well-being of women, men and children. To address the structural barriers which prevent fair shares of development gains is the prerequisite for opening up new arenas for action. The buzzword character that gender has assumed in recent years has been detrimental to such initiatives, and so have undue judgements of feminisation.

Acknowledgements. The author would like to thank the representatives of the "Geographischer Arbeitskreis Entwicklungstheorien GAE" for the Conference on Rural Development, and in particular Dörte Segebart and Theo Rauch for their comments on earlier versions of this paper. Comments of the anonymous reviewers which contributed to the clarification of the argument were also much appreciated. Last but not least my thanks go to the editing team of GH and Benedikt Korf who supervised the review process and contributed with valuable recommendations.

Edited by: B. Korf

Reviewed by: two anonymous referees

\section{References}

Alam, S.: The Effect of Gender-Based Returns to Borrowing on Intra-Household Resource Allocation in Rural Bangladesh, World Development, 40, 1164-1180, 2012.

Atkinson, R.: The life story interview. Thousand Oaks, Sage, California, 1998.

Babigumira, R., Angelsen, A., Buis, M., Bauch, S., Sunderland, T., and Wunder, S.: Forest Clearing in Rural Livelihoods: Household-Level Global-Comparative Evidence, World Development, doi:10.1016/j.worlddev.2014.03.002, 2014.

Baden, S.: Women's collective action in African agricultural markets: the limits of current development practice for rural women's empowerment, Gender \& Development, 21, 295-311, 2013.

Barham, B. L., Clark, M., Katz, E., and Schurmann, R.: Nontraditional exports in Latin America, Latin American Research Review, 27, 43-82, 1992.

Barrientos, S.: A gendered value chain approach to codes of conduct in African horticulture, World Development, 31, 1511-1526, 2003.

Barrientos, S.: Female employment in agriculture: global challenges and global responses, Commonwealth Secretariat, 2007.

Bramall, C.: Chinese economic development, Tayolor \& Francis, London, 2008.

Burgess, J., Stirling, A., Clark, J., Davies, G., Eames, M., Staley, K., and Williamson, S.: Deliberative mapping: a novel analyticdeliberative methodology to support contested science-policy decisions, Public Underst. Sci., 16, 299-322, 2007

Chant, S.: Re-thinking the "Feminization of Poverty" in relation to aggregate gender indices, Journal of Human Development, 7, 201-220, 2006.

Chant, S.: Dangerous equations? How female-headed households became the poorest of the poor: causes, consequences and cautions. Feminisms in development, in: Contradictions, contestations and challenges, edited by: Cornwall, A., Harrison, E., and Whitehead, A., Zed Books, London, 35-47, 2007a.

Chant, S.: The "feminization of poverty" in the Global South: assertions, agendas and evidence, Gender, Generation and Poverty exploring the "feminization of poverty" in Africa, Asia and Latin America, Edward Elgar, Cheltenham, 78-124, $2007 \mathrm{~b}$.

Chant, S.: Towards a (re)conceptualisation of the "feminization of poverty": reflections on gender-differentiated poverty from The Gambia, Philippines, and Costa Rica, in: The international handbook of gender and poverty. Concepts, research, policy, edited by: Chant, S., Edward Elgar, Chelthenham, 111-116, 2010.

Chhachhi, A.: Gender, flexibility, skill and industrial restructuring: The electronics industry in India, Gender, Technology and Development, 3, 329-360, 1999.

Chhachhi A. and Herrera, L.: Empire, Geopolitics and Development, Development and Change, 38, 1021-1040, 2007.

Collier, P. and Dercon, S.: African Agriculture in 50 Years: Smallholders in a Rapidly Changing World?, World Development, 63, 92-101, 2014.

Cresswell, J. W. and Plano Clark, V. L.: Designing and conduting mixed methods reserach, Sage, Thousand Oaks, 2011.

Deere, C. D.: The Feminization of agriculture? Economic restructuring in rural Latin America, UNRISD, Geneva, 2005. 
De Haan, L. and Lakwo, A.: Rethinking the impact of microfinance in Africa: "Business change" or social emancipation, European Journal of Development Research, 22, 529-545, 2006.

De Schutter, O.: The agrarian transition and the "feminization" of agriculture, New Haven, 2013.

Diao, X., Hazell, P., and Thurlow, J.: The Role of Agriculture in African Development, World Development, 38, 1375-1383, 2010.

Dolan, C. and Scott, L.: Lipstick evangelism: Avon trading circles and gender empowerment in South Africa, Gender \& Development, 17, 203-218, 2009.

Dolan, K. S. and Sorby, K.: Gender and employment in highvalue agricultural industries, Agriculture and Rural Development Working Paper, 2003.

Doss, C.: The role of women in agriculture, ESA Working Paper No. 11-02, Rome: FAO [Food and Agriculture Organization], 2011.

Ellis, F.: Rural livelihoods and diversity in developing countries, Oxford University Press, Oxford, 2000.

FAO: Decent rural empoyment: Key for poverty reduction and food security, 2010-2013: Enhancing FAO's work through decent rural employment, FAO, Rome, 2010a.

FAO: Gender dimensions of rural and agricultural employment. Differentiated pathways out of poverty, FAO, Rome, 2010b.

FAO: Women in agriculture. The State of Food and Agriculture Report, Food and Agriculture Organisation, Rome, 2011.

Faulkner, A. H. and Lawson, V. A.: Employment versus empowerment: A case study of the nature of women's work in Ecuador, J. Dev. Stud., 27, 16-47, 1991.

Ferm, N.: Non-traditional agricultural export industries: conditions for women workers in Colombia and Peru, Gender \& Development, 16, 13-26, 2008.

Gerring, J.: Case study research: principles and practices, Cambridge University Press, New York, 2009.

Hall, D., Hirsch, P., and Li, T. M.: Powers of exclusion. Land dilemmas in Southeast Asia, University of Hawaii Press, Honolulu, 2011.

Hantrais, L. and Mangen, S. P.: Methods and management of crossnational research, in: Cross-national research methods in the social sciences, edited by: Hantrais, L. and Mangen, S. P., Pinter, London, 1998.

Harris, N.: Comparative, feminism and qualitative: an uncommon perspective on cross-national social policy research, International Journal of of Qualitative Methods, 6, 27-35, 2007.

Hazell, P., Poulton, C., Wiggins, S., and Dorward, A.: The Future of Small Farms: Trajectories and Policy Priorities, World Development, 38, 1349-1361, 2010.

Henley, D.: The Agrarian Roots of Industrial Growth: Rural Development in South-East Asia and sub-Saharan Africa, Development Policy Review, 30, s25-s47, 2012.

IAASTD: Agriculture at a crossroads. International assessment of agricultural knowledge, science and technology for development, Global report, edited by: McIntyre, B., Washington, 2009.

IFAD: Rural Poverty Report, International Fund for Agricultural Development IFAD, Rome, 323 pp., 2011.

Jayne, T. S., Mather, D., and Mghenyi, E.: Principal Challenges Confronting Smallholder Agriculture in Sub-Saharan Africa, World Development, 38, 1384-1398, 2010.

Johannsson Wennerholm, C.: The "feminization of poverty". The use of a concept. SIDA, Swedish international development co- operation agency, division for policy and socio-eoconomic analysis, Stockholm, 2002.

Jones, L.: Discussion paper for an M4P WEE framework: How can the Making Markets Work for the Poor Framework work for poor women and for poor men?, The Springfield Centre for Business in Development, Durham, UK, 2012.

Kabeer, N.: Women's economic empowerment and inclusive growth: labour markets and enterprise development, SIG Working Paper, 1-65, 2012.

Kabeer, N., Mahmud, S., and Tasneem, S.: Does paid work provide a pathway to women's empowerment? Empirical findings from Bangladesh, IDS Working paper, 2011.

Kerr, R. B.: Lessons from the old Green Revolution for the new: Social, environmental and nutritional issues for agricultural change in Africa, Progress in Development Studies, 12, 213-229, 2012.

Lavers, T.: Patterns of agrarian transformation in Ethiopia: Statemediated commercialisation and the "land grab", J. Peasant Stud., 39, 795-822, 2012.

Leach, M., Scoones, I., and Stirling, A.: Dynamic sustainabilities. Technology, environment, social justice, Earthscan, London, 2010.

Li, T.: Centering labor in the land grab debate, J. Peasant Stud., 38, 281-298, 2011.

Maertens, M., Minten, B., and Swinnen, J.: Modern Food Supply Chains and Development: Evidence from Horticulture Export Sectors in Sub-Saharan Africa, Development Policy Review, 30, 473-497, 2012.

Meinzen-Dick, R., Quisumbing, A., Behrman, J., BiermayrJenzano, P., Wilde, V., Noordeloos, M., Ragasa, C., and Beintema, N.: Engendering agricultural research, IFPRI Discussion Paper 00973, New York, 2010.

Mills, M., Van de Bunt, G., and De Bruijn, J.: Comparative research, Int. Sociol., 21, 619-631, 2006.

OECD: Growing prosperity: agriculture, economic renewal, and development. Draft outcome document from the meeting "Innovation out of Poverty”, Paris, 2009.

Oya, C.: Rural labour markets in Africa: The unreported source of inequality and poverty, Development Viewpoint, 2010.

Oya, C.: Rural wage employment in Africa: methodological issues and emerging evidence, Review of African Political Economy, 40, 251-273, 2013.

Pearce, D.: The Feminization of Poverty: Women, Work and Welfare, The Urban and Social Change Review (Special Issue on Women and Work), 11, 28-36, 1978.

Pretty, J., Sutherland, W. J., Ashby, J., Auburn, J., Baulcombe, D., Bell, M., Bentley, J., Bickersteth, S., Brown, K., Burke, J., Campbell, H., Chen, K., Crowley, E., Crute, I., Dobbelaere, D., Edwards-Jones, G., Funes-Monzote, F., Godfray, H. C. J., Griffon, M., Gypmantisiri, P., Haddad, L., Halavatau, S., Herren, H., Holderness, M., Izac, A.-M., Jones, M., Koohafkan, P., Lal, R., Lang, T., McNeely, J., Mueller, A., Nisbett, N., Noble, A., Pingali, P., Pinto, Y., Rabbinge, R., Ravindranath, N. H., Rola, A., Roling, N., Sage, C., Settle, W., Sha, J. M., Shiming, L., Simons, T., Smith, P., Strzepeck, K., Swaine, H., Terry, E., Tomich, T. P., Toulmin, C., Trigo, E., Twomlow, S., Vis, J. K., Wilson, J., and Pilgrim, S.: The top 100 questions of importance to the future of global agriculture, Int. J. Agric. Sustain., 8, 219-236, 2010.

Prügl, E., Razavi, S., and Reysoo, F.: Gender and agriculture after neoliberalism, UNRISD IHEID, Geneva, 2013. 
Rahman, S.: Women's labour contribution to productivity and efficiency in agriculture: Empirical evidence from Bangladesh, J. Agr. Econ., 61, 318-342, 2010.

Razavi, S.: Export-Oriented Employment, Poverty and Gender: Contested Accounts, Development and Change, 30, 653-683, 1999.

Razavi, S.: The gendered impacts of liberalization: towards "embedded liberalism"?, Routledge/UNRISD, New York/London, ed. 2009.

Razavi, S., Arza, C., Braunstein, E., Cook, S., and Goulding, K.: Gendered impacts of globalization. Employment and social protection. UNRISD, United Nations Research Institute for Socil Development, Geneva, 2012.

Riggs, J. and Vandergeest, P. (Eds.): Revisiting rural places. Pathways to poverty and prosperity in Southeast Asia, University of Hawai'i Press, Honolulu, 2012.

Ruiz Ruiz, J.: Sociological Discourse Analysis: Methods and Logic, Forum Qualitative Sozialforschung/Forum: Qualitative Social Research, 10, Art. 26, 2009.

Sang, E. L.: Unpacking the packing plant: Nicaraguan migrant women's work in Costa Rica's evolving agriculture export sector, Signs, 35, 317-342, 2010.

Scholz, R. and Tietje, O.: Embedded Case Study Methods: Integrating Quantitative and Qualitative Knowledge, Sage, Thousand Oaks CA, 2002.

Seawright, J. and Gerring, J.: Case selection techniques in case study research: a menu of qualitative and quantitative options, Polit. Res. Quart., 61, 294-308, 2008.
Smith, S., Auret, D., Barrientos, S., Dolan, C., Kleinbooi, K., Njobvu, C., Opondo M., and Tallontire, A.: Ethical trade in African horticulture: gender, rights and participation, IDS Working Paper, 223, 1-32, 2004.

Stirling, A., Leach, M., Mehta, L., Scoones, I., Smith, A., Stagl, S., and Thompson, J.: Empowering Designs: towards more progressive appraisal of sustainability, STEPS Working Paper 3, STEPS Centre, Brighton, 2007.

UNRISD: Gender equality: striving for justice in an unequal world, United Nations Research Institute for Social Development, Geneva, 2005.

Wallander, L.: 25 years of factorial reviews in sociology: A review, Soc. Sci. Res., 38, 505-520, 2009.

WDR: Gender equality and development. World Development Report 2012, World Bank, Washington DC, 2012.

WDR: Jobs. World Development Report 2013, World Bank, Washington DC, 2013.

Whitehead, A.: The gendered impacts of liberalization policies on African agricultural economies and rural livelihoods, in: The Gendered Impacts of Liberalization: Towards "Embedded Liberalism"?, edited by: Razavi, S., Routledge, New York, 2009.

Wichterich, C.: Trading stories. Experiences with gender and trade, Gender \& Development, 18, 555-557, 2010.

Wilkinson-Weber, C.: Women, work and the imagination of craft in South Asia, Contemporary South Asia, 13, 287-306, 2004.

Yin, R. K.: Case study research, Sage, London, 2012.

Zaccaro, S.: Sustainable agriculture has a woman's face, Development, 54, 263-264, 2011. 